\title{
Expression of $\gamma-\mathrm{H} 2 \mathrm{AX}, 53 \mathrm{BP} 1$ and Micronuclei as Genome Damage Biomarker of Population in Keang and Salumati Village, Mamuju West Sulawesi Province
}

\author{
A.D. Pratiwi ${ }^{1}$, I.K.H. Basri ${ }^{2 *}$, S. Purnami ${ }^{2}$, M. Syaifudin ${ }^{2}$, D. Tetriana ${ }^{2}$, D. Yusuf ${ }^{2}$, \\ T. Rahardjo ${ }^{2}$, S. Nurhayati ${ }^{2}$, N. Rahajeng ${ }^{2}$, Y.U. Anggraito ${ }^{1}$ and I. Kashiwakura ${ }^{3}$ \\ ${ }^{I}$ Department of Biology, Faculty of Mathematics and Sciences, Semarang State University, \\ Kampus Sekaran, Gunungpati, Semarang 50229, Indonesia \\ ${ }^{2}$ Center for Radiation Safety Technology and Metrology, National Nuclear Energy Agency, \\ Jl. Lebak Bulus Raya No. 49, Jakarta 12440, Indonesia \\ ${ }^{3}$ Hirosaki University Graduate School of Health Sciences, \\ Department of Radiological Life Sciences 66-1 Hon-cho, Hirosaki, 036-856, Japan
}

\section{ARTICLE INFO}

\section{Article history:}

Received 12 April 2018

Revised in revised form 22 January 2019

Accepted 30 January 2019

\section{Keywords:}

$\gamma-\mathrm{H} 2 \mathrm{AX}$

53BP1

DNA damage

Exposed area

Control area

\begin{abstract}
A B S T R A C T
The residents living in high background radiation area have risk to be exposed by ionizing radiation that also potentially cause their DNA damage. The aim of this study was to determine the expression of $\gamma-\mathrm{H} 2 \mathrm{AX}, 53 \mathrm{BP} 1$ foci and micronuclei in the residents who live in high background radiation area of Salumati village, Mamuju, West Sulawesi, Indonesia. Twenty one blood samples which consist of 11 from the study area and 10 from control were assessed for their expression of $\gamma$-H2AX and 53BPI foci by using specific antibodies and observed under fluorescence microscope whereas micronuclei was detected after being cultured and giemsa stained according to standard procedures. Results showed that both $\gamma-\mathrm{H} 2 \mathrm{AX}$ and 53BP1foci from high background area was lower than that of control area $(0.37 \pm 0.24$ vs $0.19 \pm 0.11(\mathrm{p}=0.03)$ for $\gamma-\mathrm{H} 2 \mathrm{AX}$ and $0.61 \pm 0.30$ vs $0.31 \pm 0.12$ for 53BP1 $(\mathrm{p}=0.01))$. The mean of micronuclei frequency in exposed area was 0.02 $(0,01-0,03)$ while in control area was $0.02(0.003-0.02)$. There was statistical significant in corellation between both $\gamma-\mathrm{H} 2 \mathrm{AX}, 53 \mathrm{BP} 1$ foci with micronuclei index in exposed area ( $\mathrm{p}=0.02, \mathrm{p}=0,04$ respectively). In conclusion, there was a positive correlation between $\gamma-\mathrm{H} 2 \mathrm{AX}$ and 53BP1 foci to micronuclei and this might be a clue of the occurrence of genome repairing mechanism caused by natural radiation at low dose chronical exposure in the studied area.
\end{abstract}

(C) 2019 Atom Indonesia. All rights reserved

\section{INTRODUCTION}

Natural radiation is a major component of radiation exposure for the general population. In our natural environment, we are chronically exposed to low doses of ionizing radiation. In some situations, this environmental exposure can reach significant doses, such as in the case of some inhabited areas where the soil displays abnormally high amounts of radionuclides. There are many high-level natural radiation areas (HLNRAs) throughout the world

\footnotetext{
*Corresponding author.

E-mail address: kurnia@batan.go.id

DOI: https://doi.org/10.17146/aij.2019.847
}

such as in Brazil, China, India and Iran. The people who live in the HLNRAs of the world are of considerable interest because they have been exposed to abnormally high radiation levels over many generations [1]. Indonesia also has a region with high natural ionizing radiation. Mamuju, a city in the state of West Sulawesi off the Sulawesi Sea, has a background radiation around 13 times higher than normal. This place has the highest average dose rate compared to other regions in Sulawesi Island and even Indonesia, which can achieve up to $2.8 \mathrm{mSv} / \mathrm{h}$ [2].

Life evolved in an environment with greater levels of natural radiation than exist today. 
Natural background radiation levels on Earth vary by at least two orders of magnitude today. Therefore, all living organisms are exposed to a wide range of background radiation levels [3].

The effects of ionizing radiation on genome material are well known. Double-strand deoxyribonucleic acid (DNA) breaks is the most the primary lesions in the formation of chromosomal aberrations, which can easily be seen in metaphasic chromosomes [4].

The micronuclei is the result of chromosomal aberrations in the form of a small circle in the cytoplasm outside the main nucleus and contains the fused chromosomes or its fragments, and/or chromosomes that are intact and appear with the same structure with the main core. Micronuclei formation is highly influenced by radiation dose rate and also depends on the capacity of DNA and cellular repair [4-6].

Radiation dose and its carcinogenic effects the biological effects of low doses of radiation are not fully understood [7-9]. One of the results shows that an experimental study on the frog that is exposed with low doses irradiation above background doses indicates no reveal harmful effects of exposure to low levels of radioactivity. On the contrary, stress present in the area may serve to enhance cellular defense mechanisms [10].

Our previous study also support the hypothesis that high background radiation tend to give an adaptive response that shows in high of expression of $\gamma-\mathrm{H} 2 \mathrm{AX}$ foci that prove of repair of DNA DSB damaged process [11]. Different to our previous study, the purpose of this study is to add the parameter of 53BP1 foci and micronuclei and analyse the correlation between $\gamma-\mathrm{H} 2 \mathrm{AX}$ and 53BP1 foci to micronuclei value in control area and exposed area from the donor that living in high background natural radiation.

\section{EXPERIMENTAL METHODS}

\section{Sampling and subjects}

Before starting the study, the research proposal had been approved by Research Ethical Comission, National Institute for Health Research and Development No. LB. 02.01/5.2.KE.167/2015, signed in 5 April 2016. In this paper, 21 blood samples from residents in 2 villages (Salumati and Keang) which consist of 11 donors from Keang as control group with normal back ground exposure of $2 \mathrm{mSv} / \mathrm{year}$ and 10 samples from Salumati Village as exposed group in background exposure of $7 \mathrm{mSv} /$ year. All donors were informed about the nature, aims, and intention of the study and signed a consent form and questionnaire before providing blood samples. Any individuals suffering from an illness or taking medication were excluded.

\section{Sample preparation}

\section{Isolation of lymphocyte}

Isolation procedure was done as previously published work with some modifications. Heparinized whole blood obtained from Mamuju were transported to our laboratory in Jakarta. Histopague separation was used to isolate white blood cells by layering $2.5 \mathrm{~mL}$ of whole blood mixed with an equal volume of Phosphate Buffered Saline (PBS) pH 7.4 onto 2 vol of lymphocyteseparating medium (Histophaque 1077 Sigma Aldrich, Catalog 10771 USA) in a centrifugation tube followed by centrifugation for 30 minutes at $1500 \mathrm{rpm}$ (Thermo Scientific, Heraeus, Biofuge Primo R) [11].

\section{$\gamma-H 2 A X$ and 53BP1 assays}

Medium (RPMI) containing the isolated lymphocyte was put on hydrophobic slides and left for 15-20 min (minutes) and fixed in $2 \%$ paraformaldehyde for 5 minutes and then washed 5 minutes on ice in $0.25 \%$ Triton X-100 in PBS, and blocked in BSA (Bovine Serum Albumin) $1 \%$ in PBS for $3 \times 15$ minutes at room temperature. After removing BSA the primary anti $\gamma-\mathrm{H} 2 \mathrm{AX}$ (mouse anti-Phospho-Ser139 gamma H2AX Antibody, ThermoFisher) and anti 53BP1 Anti53BP1 (antibody ab172580) were dropped on the slides and incubated in a dark moist chamber for 1 hour at $37.5{ }^{\circ} \mathrm{C}$. To remove these first antibodies, the slides were washed with BSA 0,1 in PBS for $3 \times 15$ minutes. The second antibodies (Goat Antimouse IgG Dylight 488 and antirabbit-Dylight 594 $\mathrm{nm}$, both from Thermo Scientific) diluted in 1: 500 in BSA and with DAPI (diluted 1: 500) was added and incubated in moist chamber for 45 minutes. The slides then washed with PBS 3 x 15 minutes and dried for 15 minutes with a fan. The antivade medium with DAPI was dropped and mounting with cover slip and let for 24 hours in fridge. Observation was done by an experienced investigator (IK) using a fluorescence microscope (Nikon) equipped with red, green and blue fluorescence filters and a 100x lens under immersion oil. Generally, 50 cell per slide $\gamma-\mathrm{H} 2 \mathrm{AX}$ and 53BP1 foci were counted per individual. The observation was verified by an experienced investigator (IKHB) using a fluorescence microscope (Nikon) equipped with red, green and blue fluorescence filters and 
a 100x lens under immersion oil. Generally, $50 \gamma-\mathrm{H} 2 \mathrm{AX}$ and 53BP1 foci were counted per individual [11-14].

\section{Micronuclei assay}

Micronuclei were prepared in cytokinesis blocked cells using cytochalasin B (Cyt-B) following the method suggested by Fenech with some modifications. The whole blood cultures were incubated for 72 hours. After 44 hours of incubation cytochalasin-B (Cyt-B Sigma) was added at a concentration of $6 \mathrm{~g} / \mathrm{ml}$ to block cytokinesis. The cells were collected by centrifugation, and treated with a mild hypotonic solution containing $0.075 \mathrm{M} \mathrm{KCl}$ for $3 \mathrm{~min}$, then the cells were fixed with a fresh mixture of methanol/acetic acid (3:1). The tretated cells were dropped on to clean slides for detection of micronuclei by conventional staining with $5 \%$ Giemsa. Observation were done at least 1000 binucleated cells scored for each person for the presence of micronuclei $[15,16]$.

\section{Statistical analysis}

Kolmogoriov Smirnov Test was used to analyze data normality. Student T-Test was used to compare the mean of $\gamma-\mathrm{H} 2 \mathrm{AX}, 53 \mathrm{BP} 1$ foci, micronuclei index between control area and exposed area. The Corellation Test was used to analyze correlllation between $\gamma-\mathrm{H} 2 \mathrm{AX}$ and 53BP1 foci with micro nuclei, ages in control and exposed area. All the data were analyzed with MedCalc. Software 12.7.00.

\section{RESULTS AND DISCUSSION}

In this study, 21 donors which consist 11 from control and 10 from an exposed area can be seen in Table 1. Expression of $\gamma-\mathrm{H} 2 \mathrm{AX}$ and 53BP1 foci was showed in Figs. 1(a) and (b). The expression of $\gamma$-H2AX was detected as bright green foci. The bright foci were the result of bonding of antibody $\gamma$-H2AX with Daylight $488 \mathrm{~nm}$ secondary antibody. The expression of 53BP1 was detected as bright red foci. The bright foci were the result of bonding of antibody 53BP1 with Daylight $594 \mathrm{~nm}$ secondary antibody. Both mean $\gamma-\mathrm{H} 2 \mathrm{AX}$ and 53BP1 foci show higher in exposed than control area $(\mathrm{p}<0,05)$. Mean $\gamma-\mathrm{H} 2 \mathrm{AX}$ foci in exposed area is $0.37 \pm 0.24$ and $0.18 \pm 0.11$ in control area. The mean 53BP1 foci in exposed area is $0.61 \pm 0.30$ and $0.31 \pm 0.15$ in control area. The mean of 53BP1 foci also have lower p-value than $\gamma$-H2AX between exposed and control area ( $\mathrm{p}=0.01)$, Figs. 2(a) and (b). Micronuclei index in control area is $0.02 \pm 0.01$ with the range of 0.00-0.02 and exposed area 0.02 \pm 0.01 from 0.01-0.03 in Fig. 2c. There were no statistical difference in micronuclei index between control area and exposed area. In Figs. 3(a) and (b), there were no statistical significant correlation between both $\gamma$-H2AX and 53BP1 foci to micronulei index $(p>0,05)$ in control area, but in exposed area there were significant corellation between $\gamma$-H2AX foci to micronuclei index $(\mathrm{p}=0.02)$ as shown in Fig. 3(c) and between 53BP1 foci to micronuclei index $(\mathrm{p}=0.04)$ in Fig. 3(d).

Table 1. Characteristic donor and $\gamma-\mathrm{H} 2 \mathrm{AX}, 53 \mathrm{BP} 1$ foci and micronuclei index in control and exposed area.

\begin{tabular}{cccccccc}
\hline No & ID & Gender & Age & Location & $\gamma$-H2AX & $53 \mathrm{BP} 1$ & Micronuclei \\
\hline 1 & $\mathrm{~A}$ & $\mathrm{~L}$ & 42 & Control & 0,22 & 0,36 & 0,02 \\
\hline 2 & $\mathrm{~B}$ & $\mathrm{~L}$ & 68 & Control & 0,02 & 0,10 & 0,02 \\
3 & $\mathrm{C}$ & $\mathrm{L}$ & 53 & Control & 0,12 & 0,34 & 0,02 \\
4 & $\mathrm{D}$ & $\mathrm{P}$ & 47 & Control & 0,20 & 0,32 & 0,02 \\
5 & $\mathrm{E}$ & $\mathrm{P}$ & 31 & Control & 0,36 & 0,56 & 0,02 \\
6 & $\mathrm{~F}$ & $\mathrm{P}$ & 31 & Control & 0,28 & 0,44 & 0,02 \\
7 & $\mathrm{G}$ & $\mathrm{P}$ & 51 & Control & 0,06 & 0,10 & 0,02 \\
8 & $\mathrm{H}$ & $\mathrm{L}$ & 46 & Control & 0,08 & 0,14 & 0,00 \\
9 & $\mathrm{I}$ & $\mathrm{L}$ & 44 & Control & 0,34 & 0,54 & 0,01 \\
10 & $\mathrm{~J}$ & $\mathrm{~L}$ & 24 & Control & 0,26 & 0,32 & 0,01 \\
11 & $\mathrm{~K}$ & $\mathrm{~L}$ & 44 & Control & 0,10 & 0,26 & 0,01 \\
12 & $\mathrm{~L}$ & $\mathrm{~L}$ & 46 & Exposed & 0,44 & 0,54 & 0,02 \\
13 & $\mathrm{M}$ & $\mathrm{P}$ & 60 & Exposed & 0,30 & 0,42 & 0,02 \\
14 & $\mathrm{~N}$ & $\mathrm{~L}$ & 40 & Exposed & 0,22 & 0,42 & 0,01 \\
15 & $\mathrm{O}$ & $\mathrm{P}$ & 25 & Exposed & 0,40 & 0,68 & 0,02 \\
16 & $\mathrm{P}$ & $\mathrm{P}$ & 40 & Exposed & 0,94 & 1,24 & 0,02 \\
17 & $\mathrm{Q}$ & $\mathrm{L}$ & 67 & Exposed & 0,18 & 0,62 & 0,01 \\
18 & $\mathrm{R}$ & $\mathrm{L}$ & 72 & Exposed & 0,60 & 0,98 & 0,03 \\
19 & $\mathrm{~S}$ & $\mathrm{P}$ & 67 & Exposed & 0,08 & 0,18 & 0,01 \\
20 & $\mathrm{~T}$ & $\mathrm{P}$ & 24 & Exposed & 0,36 & 0,54 & 0,01 \\
21 & $\mathrm{U}$ & $\mathrm{L}$ & 27 & Exposed & 0,20 & 0,50 & 0,02 \\
\hline & & & & & & &
\end{tabular}

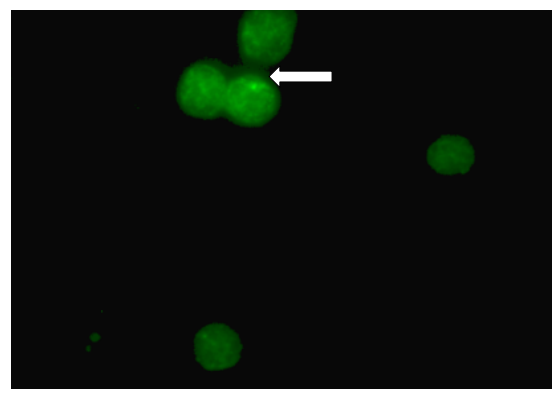

(a)

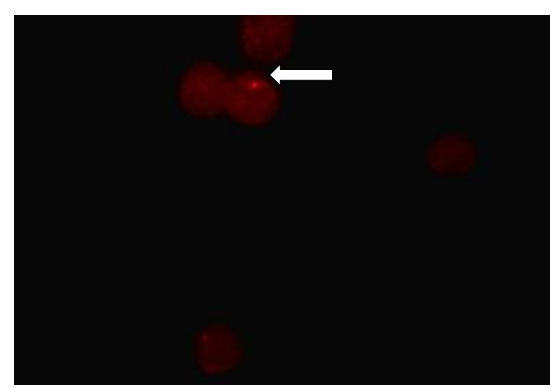

(b)

Fig. 1. Expression of $\gamma-\mathrm{H} 2 \mathrm{AX}$ foci (a) and 53BP1 foci (b). 


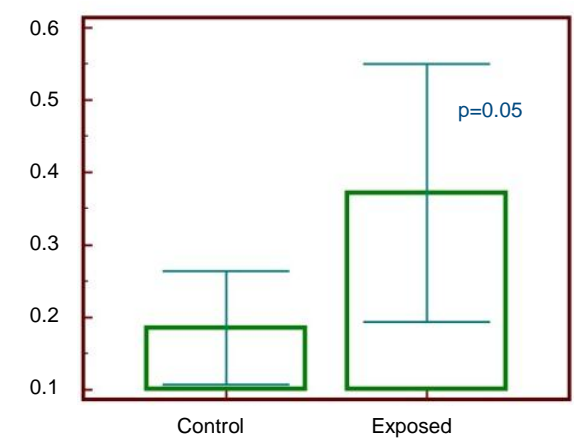

(a)

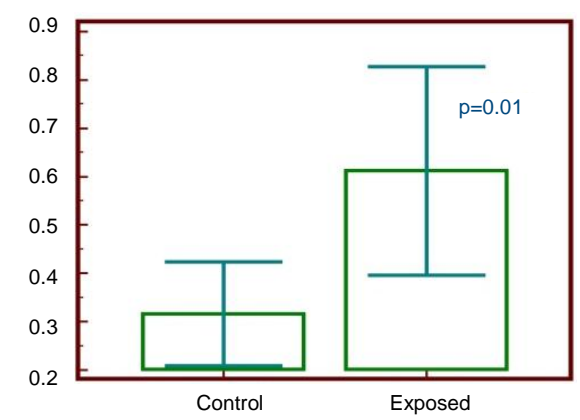

(b)

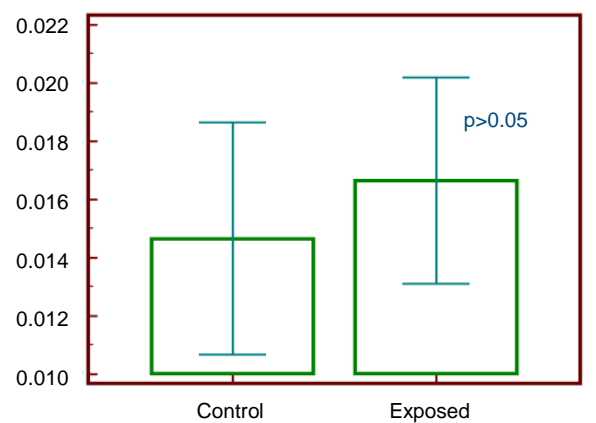

(c)

Fig. 2. $\gamma-\mathrm{H} 2 \mathrm{AX}$ (a) 53BP1 (b) foci and micronuclei index (c) in control area and exposed area.

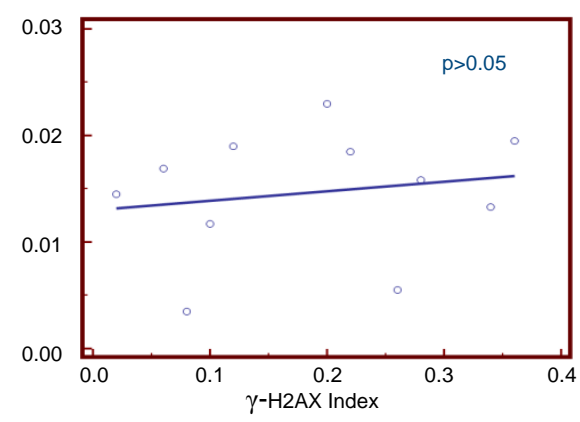

(a)

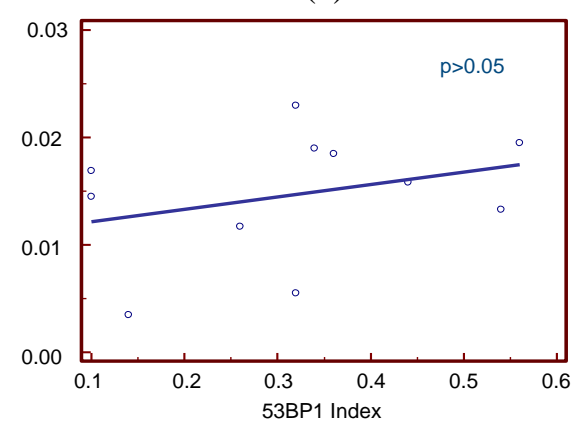

(b)

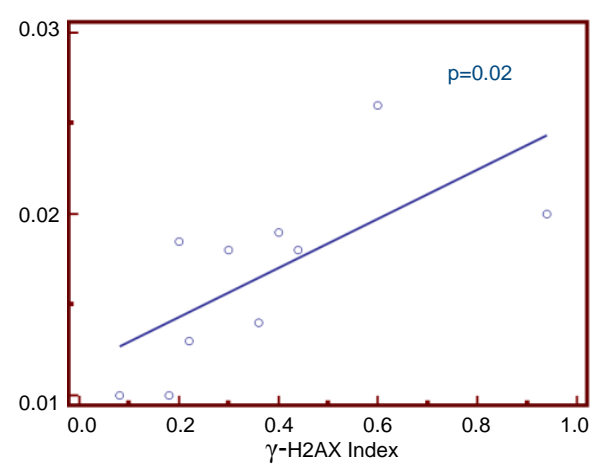

(c)

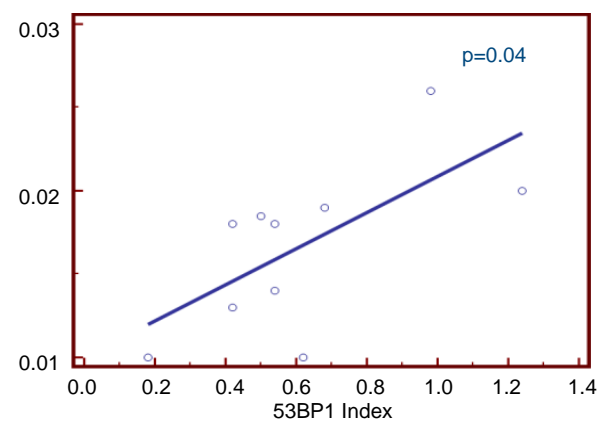

(d)

Fig. 3. Corellation between $\gamma-\mathrm{H} 2 \mathrm{AX}$ and 53BP1 foci index with micronulei index in control area $(\mathrm{a}, \mathrm{b})$ and in exposed area $(\mathrm{c}, \mathrm{d})$.

As seen in Table 2 there is a correlation between the ages of volunteer to $\gamma-\mathrm{H} 2 \mathrm{AX}$ and 53BP1 foci in control area $(\mathrm{p} \leq 0,05$ and $\mathrm{p}=0.05)$, respectively but no correllation in exposed area, there were no statistical significant corellation between the ages and micronuclei index both in control and exposed area.

Table 2. Corellation between $\gamma-\mathrm{H} 2 \mathrm{AX}, 53 \mathrm{BP} 1$ foci and micronuclei index age of donor in control and exposed area.

\begin{tabular}{llcc}
\hline \multirow{2}{*}{ No } & \multirow{2}{*}{ Genome damage biomarker } & \multicolumn{2}{c}{$\mathrm{p}$ value } \\
\cline { 3 - 4 } & & Control area & Exposed area \\
\hline 1 & $\gamma$-H2AX & $<0,05$ & $>0,05$ \\
2 & 53 BP1 & 0,05 & $>0,05$ \\
3 & Micronuclei & $>0,05$ & $>005$ \\
\hline
\end{tabular}

People are continuously exposed to natural background radiation. The level of exposure varies from place to place due to altitude and radioactive mineral deposits. The most prominent high-level natural radiation areas (HLNRA) include Guarapari, Brazil; Yangjiang, China; Kerala, India; and Ramsar, Iran. Smilar with these areas, Mamuju West Sulawesi also has a high-level natural radiation exposures [2]. In certain areas, levels of natural radiation exposure are much higher $(10-100 x)$ compared to normal levels, due to the presence of radioactivity in soils, rocks, or hot springs. In Kerala annual dose reached $13 \mathrm{mSv} / \mathrm{y}$, and China up to $5.3 \mathrm{mSv} / \mathrm{y}[17,18]$. The area has populations residing 
in there are exposed to low dose/low-dose-rate radiation for generations, throughout their lives. The effect of low dose and low dose-rate exposure below $100 \mathrm{mSv}$ has important implications in radiation protection science. The linear-no-threshold (LNT) dose-response relationship extrapolates to low-dose exposures from high acute-dose exposures. Studies of persons from HLNRA provide an opportunity to understand better the biological effects of low-dose exposures [19,20].

Different with previous publication [11], in this publication 53BP1 foci is not only used as internal control and both donors from exposed area and control area was collected from another sub-villages in Mamuju, West Sulawesi. In this paper, potential DSB DNA damage as detected by $\gamma-\mathrm{H} 2 \mathrm{AX}$ and total DNA damaged with 53BP1 and also analyse the micronuclei as other genome damage biomarker. It was found that consistency or confirm with previous report [11] there higher numbers of $\gamma-\mathrm{H} 2 \mathrm{AX}$ foci per cell in individuals of the exposed area than control area. The same result also showed in the mean of 53BP1 foci in exposed and control area. It means that some process of damaged DNA repair both single strand break and double-strand break that signed by the existences of $\gamma-\mathrm{H} 2 \mathrm{AX}$ and 53BP1 foci. It suggested that this damaged DNA repair process is the part of adaptive response cell mechanism that caused by chronical of low doses natural radiation exposure. It is also predicted that this is part of cell or DNA respons to prevent continued DNA damage or cell death.

It is almost surely that higher levels of environmental radiation are always equal to higher rates of micronuclei (MN) [21]. In this study micronuclei index in control and exposed area was not different. The same with these result, Mohammadi et al. [22,23], report that no significant difference found in basal MN frequencies between individuals from high background radiation areas and control areas in Ramsar, Iran. It is different with result from Karuppasamy et al. [19] who reported that micronuclei index in pheripheral lymphocyte from the men living in high exposed area is higher than that from lower exposed area of natural radiation in Kerala India.

The significant correlation was found between both $\gamma-\mathrm{H} 2 \mathrm{AX}$ and 53BP1 foci with micronuclei index in exposed area. The process of DNA damage in general and specially in DNA DSB repair are occur in $\mathrm{G} 2$ or adaptive checkpoint before the cell entering the mitotic phase. Lewis and Goldstein [24] found that, production of micronuclei were correlated to checkpoint adaptation as part of process that contribute to genomic change. These processes were indicated by high expression of $\gamma-\mathrm{H} 2 \mathrm{AX}$ and 53BP1 foci. In this study, positive corellation between $\gamma-\mathrm{H} 2 \mathrm{AX}$ and 53BP1 foci as biomarkers of DNA damage repairing damage mechanism to high expression of micronulei maybe also related to genome change that inducing radioresistance. Mortazavi et al., [25], prolonged exposure to very high levels of natural radiation could induce the phenomena leading to induction of a considerable radioresistance in the inhabitants.

The volunter ages factor shows any correllation with genome damage repairing that detected with $\gamma-\mathrm{H} 2 \mathrm{AX}$ and 53BP1 foci in control but in contrast no statistically corelllation in exposed area. It may be related to decreasing of DNA repair capacity in the people when the age is getting older. Maybe without reach limit doses natural radiation exposure the DNA damage repair capacity the same with other people that living in back ground radiation exposure. In this study also seem that DNA DSB repair capacity that detected by $\gamma-\mathrm{H} 2 \mathrm{AX}$ foci was likely more affected by the ages than total DNA damage that detected by 53BP1 eventhough in current result the number of sample was limited. Garm et al. [26] stated that age in this range did not seem to have any effect on the SSB parameters. However, $\gamma-\mathrm{H} 2 \mathrm{AX}$ foci response and DSB repair capacity decreased with increasing age. Expression of $\gamma-\mathrm{H} 2 \mathrm{AX}$ foci in this study was related to DNA DSB damage repair process because about 8 hours need from blood collection location to laboratory to prepare lymphocyte isolation. Rothkamm and Horn [27], the number of $\gamma-\mathrm{H} 2 \mathrm{AX}$ foci increases rapidly and reaches a maximum a few minutes after exposure. It then declines rapidly, closely following the kinetics of DSB repair.

The similar with this study the ages have no significant corellation to $\gamma-\mathrm{H} 2 \mathrm{AX}, 53 \mathrm{BP} 1$ foci and micronuclei index in exposed area [28]. Its maybe related to difference of DSBs damaged repaired and forming of micronuclei in exposed area were not be influenced by the ages of resident. In our previous publication, there were also no statistical significant between the age and expresssion $\gamma-\mathrm{H} 2 \mathrm{AX}$ and 53BP1 foci [11]. Different result with Syaifudin et al., [29] the expression of micronucleus in control and exposed area have positive corellation with the resident ages. The elevate of $\mathrm{MN}$ with age is likely due to a combination of factors which include (i) the accumulation effect of acquired mutations in genes involved in DNA repair, chromosome segregation and cell cycle checkpoint and (ii) numerical and structural aberrations in chromosomes caused by exposure to endogenous genotoxins, inadequate nutrition, exposure to environmental or occupational genotoxins, as well as a wide range of unhealthy lifestyle factors [30]. From this result 
may also can seen the expression of $\mathrm{MN}$ that directly related to the decreasing of DNA repair of the resident that living in exposed area have not indicate the decrease of repair capacity and genome instability. In generally been shown that a higher $\mathrm{MN}$ frequency is directly associated with decreased eficiency of DNA repair and increased genomic instability $[30,31]$.

\section{CONCLUSION}

There is a correlation between $\gamma-\mathrm{H} 2 \mathrm{AX}$ and 53BP1 foci to micronuclei index in lymphocyte of resident of exposed area that maybe a clue of the genome repairing mechanism to DNA damage caused by natural radiation at low dose chronical exposure in studied area. No significant indication that any decreasing eficiency and increasing genomic instabilty in the resident that living in exposed area.

\section{ACKNOWLEDGMENT}

This study was supported by Annual Research and Development Grant from Center For Technology of Radiation Safety and Metrology, National Nuclear Energy Agency (080.01.06 3447.001 001052.A). We also would like to thank you very much for Mr. Abarrul Ikram, The head of Center for Technology of Radiation Safety and Metrology, National Nuclear Energy Agency, and all person who supported this study both in the field of Mamuju and laboratory.

\section{REFERENCES}

1. S.M.J. Mortazavi, A. Abbasi, R. Asadi et al., International Congress Series, Elsevier 1276 (2005) 440.

2. H. Syaeful, I.G. Sukadana and A. Sumaryanto, Atom Indonesia 40 (2014) 33.

3. S.M.J. Mortazavi and PA. Karam, Radioactivity in the Environment 7 (2005) 1141.

4. H. Romm, E. Ainsbury, S. Barnard et al., Health Phys. 106 (2014) 764.

5. A. Vral, M. Fenech and H. Thierens, Mutagenesis 26 (2011) 11.

6. J.D. Tucker, M. Vadapalli, M.C. Joiner et al., Radiat. Res. 180 (2013) 284.

7. E. Pernot, J. Hall, S. Baatout et al., Mutation Res. 751 (2012) 258.

8. I.B. Mosse, J.Environ. Radioact. 112 (2012) 70.
9. T. Revenco, G. Lapouge, V. Moers et al., Stem Cells 35 (2017) 1355.

10. M. Audette-Stuart, S.B. Kim, D. McMullin et al., J. Environ. Radioact. 102 (2011) 566.

11. I.K.H. Basri, D. Yusuf, T. Rahardjo et al., J. Environ. Radioact. 171 (2017) 212.

12. M. Sánchez-Flores, E. Pásaro, S. Bonassi et al., Toxicological Sciences 144 (2015) 406.

13. K. Rothkamm, S. Barnard, E.A. Ainsbury et al., Mutation Research/Genetic Toxicology and Environmental Mutagenesis 756 (2013) 170.

14. U. Eberlein, H. Scherthan, C. Bluemel et al., J. Nuc. Med. 57 (2016) 173.

15. F.N. Flegal, Y. Devantier, J.P. McNamee et al., Health Phys. 98 (2010) 276.

16. M. Syaifudin, Y. Lusiyanti, S. Purnami et. al., Atom Indonesia 43 (2017) 47.

17. M. Hosoda, S. Tokonami, Y. Omori et al., PLoS One 17 (2015) e 0124433.

18. H. Kudo, S. Tokonami, Y. Omori et al., Radiat. Prot. Dosimetry 167 (2015) 155.

19. C.V. Karuppasamy, E.N. Ramachandran, V.A. Kumar et al., Mutation Research/Genetic Toxicology and Environmental Mutagenesis 800 (2016) 40.

20. E.N. Ramachandran, C.V. Karuppasamy, V.A.Kumar et al., Mutagenesis 32 (2017) 267.

21. S.M.J. Mortazavi and H. Mozdarani, Int. J. Radiation Research 11 (2013) 3.

22. S. Mohammadi, M.T. Dehaghani, M.R. Gharati et al., J.Radiat. Res.47(2006) 279.

23. B. Das, BARC Newsletter (2010) 28.

24. C.W. Lewis and R.M. Golsteyn, Cell. Cycle. 15 (2016) 3131.

25. A.C. Geetha and H. Sreedharan, Int. J. Adv. Res. Biol. Sci. 3 (2016) 163.

26. C. Garm, M. Moreno-Villanueva, A. Bürkle et al., Aging Cell. 12 (2013) 58.

27. K. Rothkamm and S. Horn, Ann. Ist. Super. Sanità 45 (2009) 265.

28. M. Shahla, M. Taghavi-Dehaghani, M.R. Gharaati et al., J. Radiat. Res. 47 (2006) 279.

29. M. Syaifudin, S. Purnami, T. Rahardjo et al., Radiation Environment and Medicine 7 (2018) 65.

30. M. Fenech, Michael and S. Bonassi, Mutagenesis 26 (2011) 43.

31. H. Nefic and I. Handzic, Mutation Research/Genetic Toxicology and Environmental Mutagenesis 753 (2013) 1. 